\title{
Effect of Deposition and Annealing Temperature on Structural, Electrical and Optical Properties of Ag Doped ZnO Thin Films
}

\author{
Eun-Kyung Jeong, In Soo Kim, Dae-Hyun Kim and Se-Young Choi \\ School of Materials Science \& Engineering, Yonsei University, 134 Shinchondong, \\ Seodaemungu, Seoul 120-749, Rep. of Korea
}

(Received December 17, 2007 : Accepted January 22, 2008)

\begin{abstract}
The effects of the deposition and annealing temperature on the structural, electrical and optical properties of $\mathrm{Ag}$ doped $\mathrm{ZnO}(\mathrm{ZnO}: \mathrm{Ag})$ thin films were investigated. All of the films were deposited with a $2 \mathrm{wt} \%$ $\mathrm{Ag}_{2} \mathrm{O}$-doped $\mathrm{ZnO}$ target using an e-beam evaporator. The substrate temperature varied from room temperature (RT) to $250^{\circ} \mathrm{C}$. An undoped $\mathrm{ZnO}$ thin film was also fabricated at $150^{\circ} \mathrm{C}$ as a reference. The as-grown films were annealed in temperatures ranging from 350 to $650^{\circ} \mathrm{C}$ for $5 \mathrm{~h}$ in air. The $\mathrm{Ag}$ content in the film decreased as the deposition and the post-annealing temperature increased due to the evaporation of the $\mathrm{Ag}$ in the film. During the annealing process, grain growth occurred, as confirmed from XRD and SEM results. The as-grown film deposited at RT showed n-type conduction; however, the films deposited at higher temperatures showed p-type conduction. The films fabricated at $150^{\circ} \mathrm{C}$ revealed the highest hole concentration of $3.98 \times 1019 \mathrm{~cm}^{-3}$ and a resistivity of $0.347 \Omega \cdot \mathrm{cm}$. The RT PL spectra of the as-grown $\mathrm{ZnO}: \mathrm{Ag}$ films exhibited very weak emission intensity compared to undoped $\mathrm{ZnO}$; moreover, the emission intensities became stronger as the annealing temperature increased with two main emission bands of near band-edge UV and defect-related green luminescence exhibited. The film deposited at $150^{\circ} \mathrm{C}$ and annealed at $350^{\circ} \mathrm{C}$ exhibited the lowest value of $I_{v i s} /$ $I_{w}$ of 0.05 .
\end{abstract}

Key words p-type $\mathrm{ZnO}$, e-beam evaporation, photoluminescence, Ag doping.

\section{Introduction}

$\mathrm{ZnO}$ is a II-VI compound semiconductor material which has a direct wide band gap of $3.37 \mathrm{eV}$ and high exciton binding energy of $60 \mathrm{meV}$ at room temperature. The exciton binding energy of $\mathrm{ZnO}$ is higher than that of $\mathrm{GaN}(25 \mathrm{meV})$ and $\mathrm{ZnSe}(20 \mathrm{meV}){ }^{1)}$ The large exciton binding energy would allow for stable high-yield luminescence even at room temperature. Currently, $p$-type doping of $\mathrm{ZnO}$ has attracted great attention because it is essential for realizing $\mathrm{ZnO}$ based devices such as UV and blue light emitting diodes and lasers which have great potential in the reduction of energy consumption. However, it is difficult to achieve sufficiently highquality $p$-type $\mathrm{ZnO}$ with low resistivity and high mobility because undoped $\mathrm{ZnO}$ is usually $n$-type, which is associated with native donor defects such as oxygen vacancy $\mathrm{V}_{\mathrm{O}}$ or interstitial zinc $\mathrm{Zn}_{\mathrm{i}}$ and/or hydrogen residual hydrogen impurities. ${ }^{2-6}$ To compensate and suppress the native donor defects, it is needed to find proper $p$-type

Corresponding author

E-Mail : sychoi@yonsei.ac.kr (S. Y. Choi) dopant material. Many research groups have reported group I ( $\mathrm{Li}, \mathrm{Na}$ and $\mathrm{K}){ }^{7-9)}$ group $\mathrm{V}(\mathrm{N}, \mathrm{P}, \mathrm{Sb}$ and $\mathrm{As}){ }^{10-15)}$ and group IB $(\mathrm{Cu} \text { and } \mathrm{Ag})^{16-19)}$ elements as $p$-type dopants. It was found that lithium tends to occupy the interstitial sites due to its small atomic radii, and therefore acts as a donor or deep trap. It was also reported that the bonding lengths of $\mathrm{Na}$ and $\mathrm{K}$ are much longer than the ideal $\mathrm{Zn}$ -

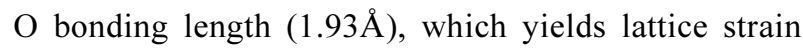
resulting in native defects that will compensate for any acceptor states that may form. To avoid this problem, doping with group IB elements was theoretically suggested $^{20)}$ and a very few reports are available on $p$ type $\mathrm{ZnO}$ with $\mathrm{Ag}$ doping deposited by sputtering method and PLD. ${ }^{17-19)}$

In this work, realization of $p$-type $\mathrm{ZnO}$ thin films by ebeam evaporation of $\mathrm{ZnO}: \mathrm{Ag}_{2} \mathrm{O}$ target are reported. The e-beam evaporation method has several advantages. It is suitable for large area deposition and source target can easily be replaced and the deposition rate in this process can be as low as $1 \mathrm{~nm}$ per minute to as high as few micrometers per minute. The material utilization efficiency is high relative to other methods and the process offers structural and morphological control of films. Systematic 
study of electrical, structural and optical properties of the $\mathrm{ZnO}: \mathrm{Ag}$ thin films was investigated as a function of deposition and annealing temperatures.

\section{Experiments Procedure}

Target was prepared from powder mixture of $\mathrm{ZnO}$ (99.9\%, Cerac, U.S.A.) and $2 \mathrm{wt} \%$ of $\mathrm{Ag}_{2} \mathrm{O}(99 \%$, Kojima Chemicals, Japan). The powder mixtures were ground for $24 \mathrm{~h}$ with zirconia balls in ethanol, and then dried at $110^{\circ} \mathrm{C}$. Dry powder mixtures were uniaxially cold-pressed into disks at a pressure of 2000 psi. Heat treatment at $1400^{\circ} \mathrm{C}$ was then performed for $4 \mathrm{~h}$ in a box furnace for densification. The $\mathrm{ZnO}: \mathrm{Ag}$ thin films were deposited by e-beam evaporator (SNTek, Korea). Before deposition, the chamber was evacuated down to $5 \times 10^{-6}$ Torr. High voltage and current of electron gun were kept at $5.10 \mathrm{kV}$ and 20-27 mA, respectively. Substrate temperature was measured using a bending thermocouple attached to the slide glass, and was varied from RT to $250^{\circ} \mathrm{C}$. The substrate was rotated at a rate of $20 \mathrm{rpm}$ for uniform deposition. As-deposited thin films underwent a postannealing process in a temperature range from 350 to $650^{\circ} \mathrm{C}$ for $5 \mathrm{~h}$ in air. Heating rate was kept constant at $10^{\circ} \mathrm{C} / \mathrm{min}$. All annealed films were vacuum-packed to avoid further contamination.

The compositions of the films were investigated using electron probe x-ray micro analysis (EPMA, JXA-8900R, Jeol, Japan). The crystal orientation was investigated with X-ray diffractometer (XRD, Rigaku Japan, D/max-II) with $\mathrm{Cu} \mathrm{K} \alpha$ radiation. Images of the microstructure were obtained using field emission scanning electron microscope (FE-SEM, S4200, Hitach, Japan) with $\times 60,000$ magnification. Electrical properties were measured using Hall effect measurement system (HMS-3000, ECOPIA, Korea) using Van der Pauw method. The magnetic field was $0.53 \mathrm{~T}$ and indium electrode was made on the film. The photoluminescence was measured at room temperature with a $\mathrm{He}-\mathrm{Cd}$ laser of $325 \mathrm{~nm}$ in wavelength and a power of $50 \mathrm{~mW}$ as the excitation source (PL, SPEX1403, USA).

\section{Result and discussion}

Figure 1 shows $\mathrm{Ag}$ content in accordance with the deposition and annealing temperature. The Ag contents of the films were calculated using the equation, $\mathrm{Ag} /(\mathrm{Ag}+$ $\mathrm{Zn}$ ). As shown in Figure 1 (a), Ag content of the film
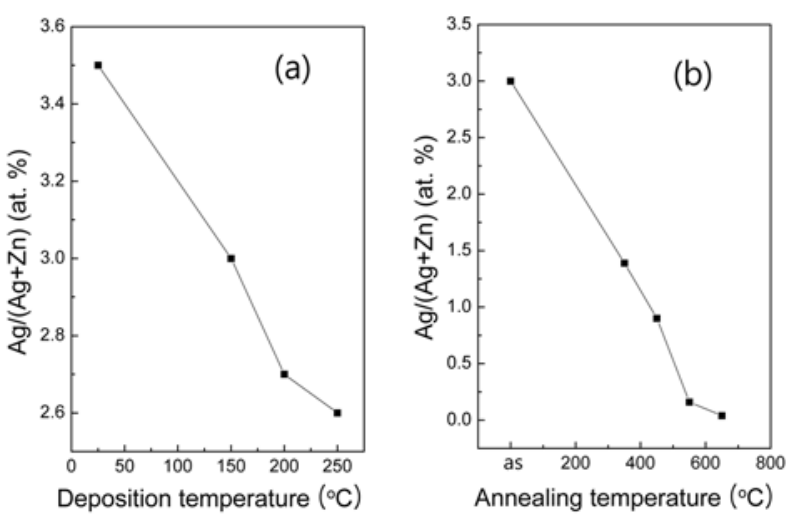

Fig. 1. Variation of $\mathrm{Ag}$ content according to (a) deposition temperature, and (b) annealing temperature.

deposited at RT was $3.5 \mathrm{at} \%$ however, the $\mathrm{Ag}$ content continuously decreased to 2.6 at $\%$ as the deposition temperature increased. It is considered that re-evaporation of thermally activated $\mathrm{Ag}$ atoms from the substrate occurred. The binding energy of Ag-O, $220.1 \pm 20.9 \mathrm{~kJ} / \mathrm{mol}$, and $\mathrm{Ag}-\mathrm{Ag}$, $160.3 \pm 3.4 \mathrm{~kJ} / \mathrm{mol}$ are higher than $159 \pm 4 \mathrm{~kJ} / \mathrm{mol}$ of $\mathrm{Zn}$ $\mathrm{O}$ and $29 \mathrm{~kJ} / \mathrm{mol}$ of $\mathrm{Zn}-\mathrm{Zn}$. The melting points of $\mathrm{Ag}$ and $\mathrm{Zn}$ are $961^{\circ} \mathrm{C}$ and $419^{\circ} \mathrm{C}$, respectively. Thus, it is expected that $\mathrm{Zn}$ atoms will evaporate more during the postannealing process, and as a result, Ag content ratio would increase. However, the results were totally opposite from what we expected. Ag content ratio decreased instead of $\mathrm{Zn}$ with increasing annealing temperature. In the literature, ${ }^{21)}$ it was reported that $\mathrm{Ag}_{2} \mathrm{O}$ molecules begin to decompose at about $200^{\circ} \mathrm{C}$, and at $250-300^{\circ} \mathrm{C}$, decomposition takes place rapidly and it also breaks up into its constituents in sunlight. Additionally, the melting point of $\mathrm{ZnO}$ is $1975^{\circ} \mathrm{C}$, which is much higher than the decomposition temperature of $\mathrm{Ag}_{2} \mathrm{O}$. Thus, we concluded that $\mathrm{Ag}$ decomposed from $\mathrm{Ag}_{2} \mathrm{O}$ is easier to evaporate than $\mathrm{Zn}$ bonded to oxygen.

Figure 2 shows the XRD spectra with the variation of deposition temperature. According to the previous reports, ${ }^{22)}$ $\mathrm{ZnO}$ thin film tends to grow with c-axis preferred orientation. The (002) plane is the close-packed plane of hexagonal structure, so thin films grow along the c-axis that is perpendicular to the substrate to reduce the surface free energy. ${ }^{18,23-24)}$ However, the thin films deposited at different temperatures show different diffraction peak intensities. Additionally, as the annealing temperature increased, the intensity of (101) became stronger instead of (002). Figure 3 shows the SEM images of $550^{\circ} \mathrm{C}$ annealed films and the films have some voids on their 

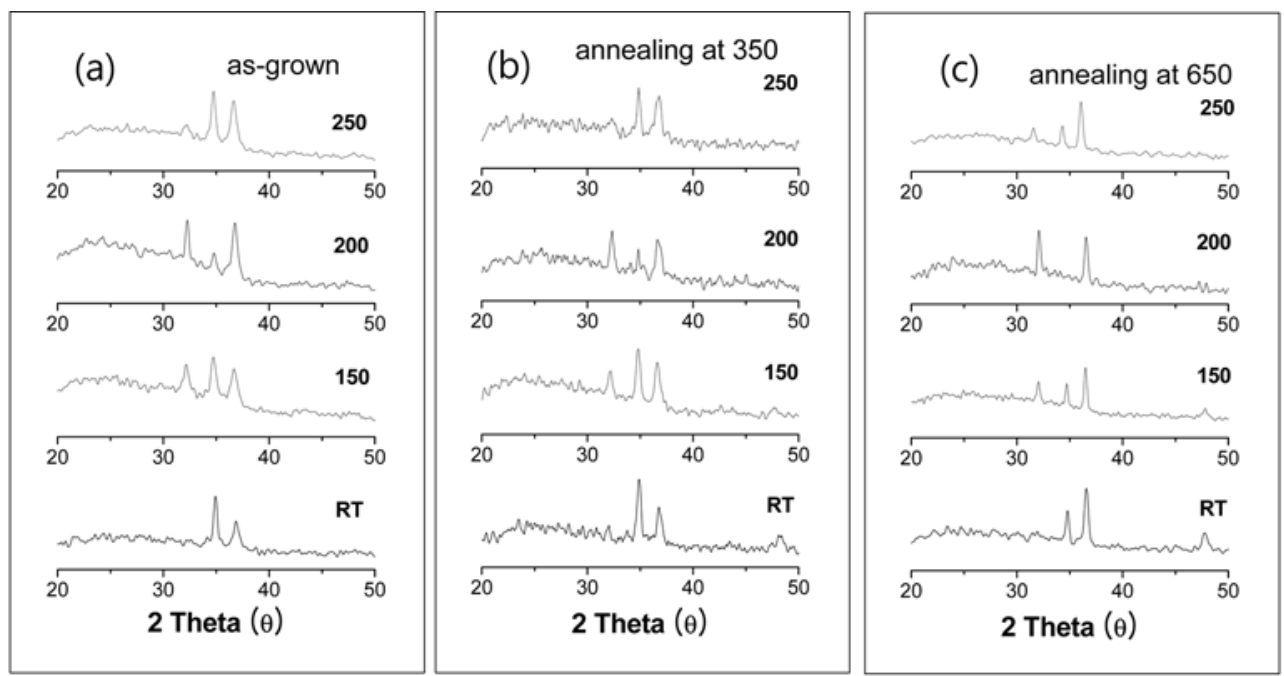

Fig. 2. XRD spectra of the films deposited at temperatures between $\mathrm{RT}$ and $250^{\circ} \mathrm{C}$ in accordance with different annealing temperatures; (a) as-grown films (b) $350^{\circ} \mathrm{C}$ annealed films, and (c) $650^{\circ} \mathrm{C}$ annealed films.

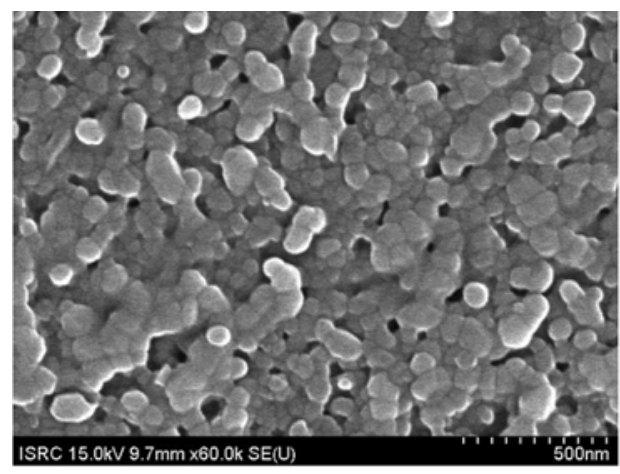

(a)

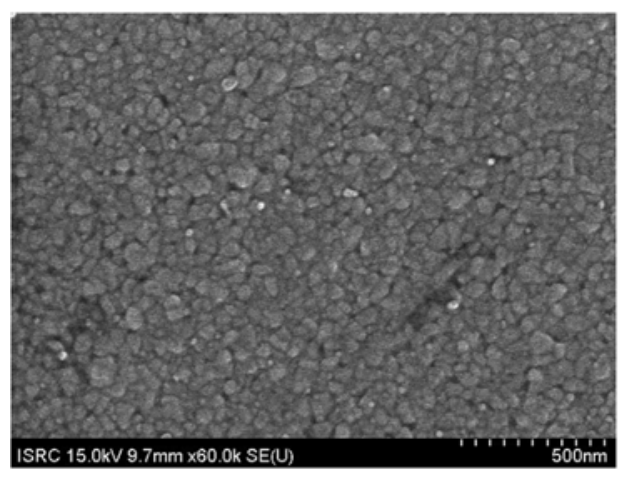

(c)

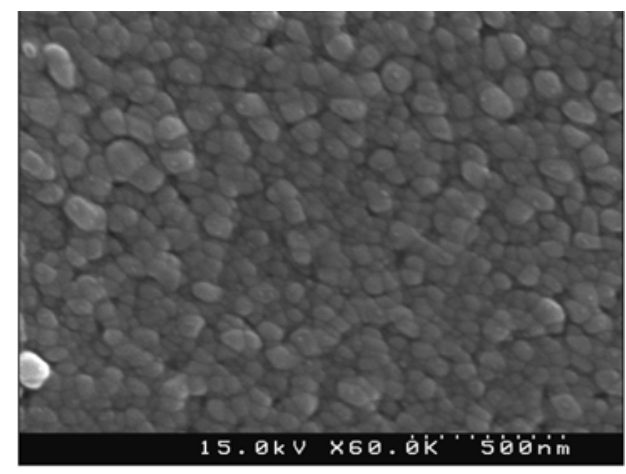

(b)

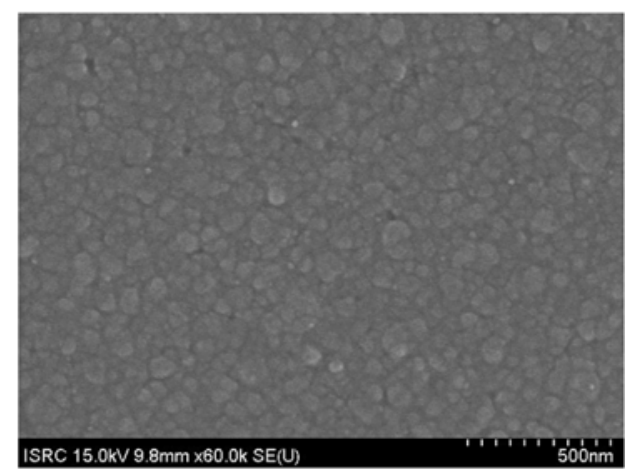

(d)

Fig. 3. Surface microstructures of the films annealed at $550^{\circ} \mathrm{C}$; films deposited at (a) RT, (b) $150^{\circ} \mathrm{C}$, (c) $200^{\circ} \mathrm{C}$, and (d) $250^{\circ} \mathrm{C}$.

surface. Of these annealed samples, especially, RT deposited thin film has very large voids, making the surface look very porous. It is believed that RT deposited thin film had more Ag content compared with the others deposited at higher temperatures.

Figure 4 shows the XRD spectra of $150^{\circ} \mathrm{C}$ deposited films according to annealing temperature. The full width at half maximum (FWHM) values of the $\mathrm{ZnO}: \mathrm{Ag}$ films were found to be $0.46^{\circ}, 0.36^{\circ}, 0.37^{\circ}, 0.36^{\circ}$, and $0.29^{\circ}$ for as deposited and annealed at $350^{\circ} \mathrm{C}, 450^{\circ} \mathrm{C}, 550^{\circ} \mathrm{C}$ and $650^{\circ} \mathrm{C}$ films, respectively. The FWHM value of undoped $\mathrm{ZnO}$ film was $0.34^{\circ}$. From FWHM of the diffraction peaks, 

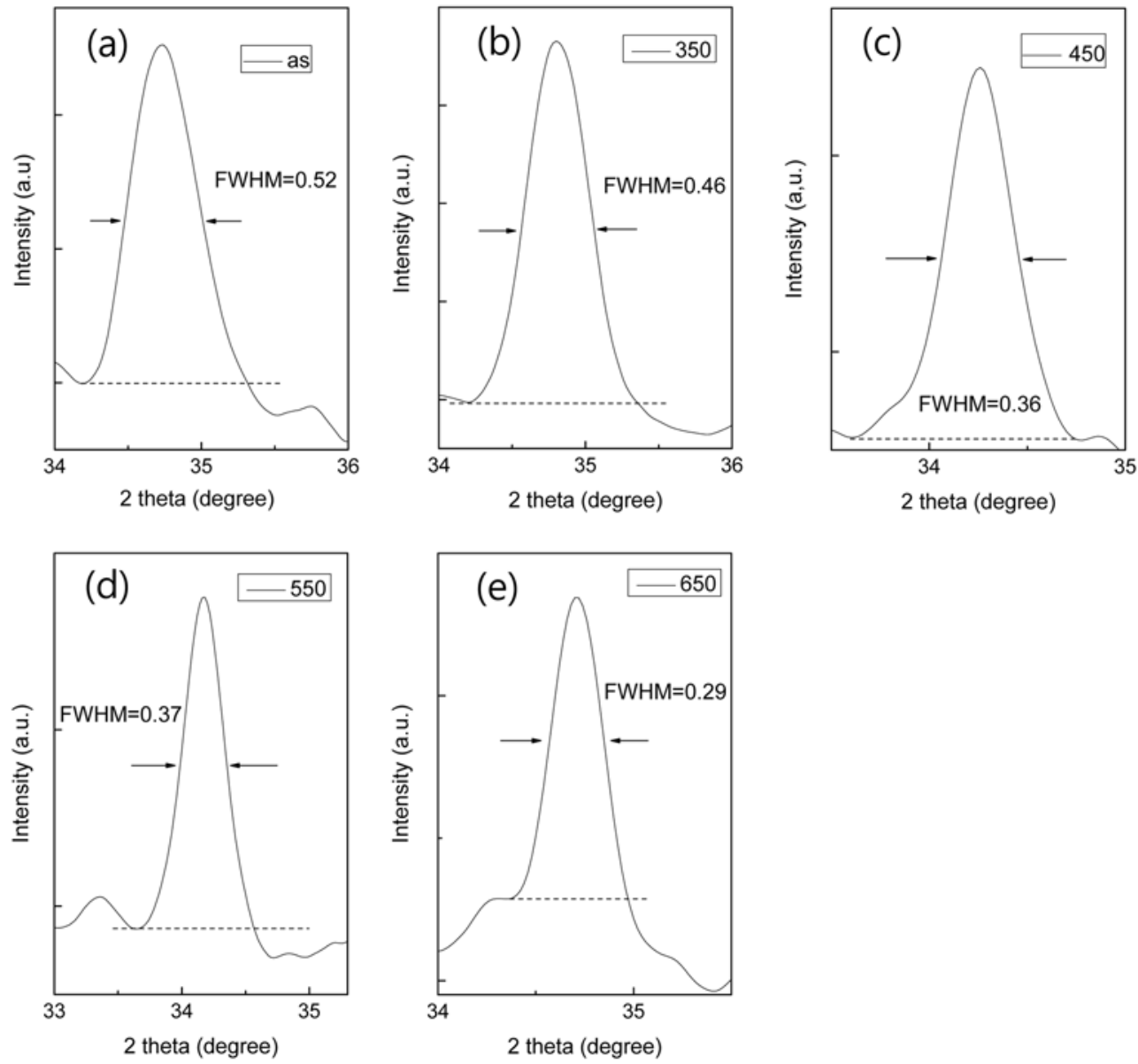

Fig. 4. X-ray diffraction patterns of (002) plane obtained from $\mathrm{ZnO}$ :Ag films grown at $150^{\circ} \mathrm{C}$; (a) as-grown, (b) annealed at $350^{\circ} \mathrm{C}$, (c) annealed at $450^{\circ} \mathrm{C},(\mathrm{d})$ annealed at $550^{\circ} \mathrm{C}$, and (e) annealed at $650^{\circ} \mathrm{C}$.

one can calculate the average diameters of the crystals using the Scherrer formula. ${ }^{25)}$ The decrease in FWHM value means an increase in grain size. Although Ag evaporated, recrystallization occurred during postannealing process, and this was confirmed from micro- structure images. Figure 5 shows the surface microstructure of $150^{\circ} \mathrm{C}$ deposited films with annealing temperature. The grain size increased gradually as the annealing temperature increased.

Table 1 shows the electrical properties of $\mathrm{ZnO}: \mathrm{Ag}$ thin

Table 1. Electrical properties of undoped and $\mathrm{Ag}$ doped $\mathrm{ZnO}$ films measured by Hall effect measurement system

\begin{tabular}{|c|c|c|c|c|c|}
\hline $\begin{array}{c}\text { Deposition temp } \\
\left({ }^{\circ} \mathrm{C}\right)\end{array}$ & $\begin{array}{l}\text { Annealing } \\
\text { temp. }\left({ }^{\circ} \mathrm{C}\right)\end{array}$ & $\begin{array}{l}\text { Carrier Conc. } \\
\left(\# / \mathrm{cm}^{3}\right)\end{array}$ & $\begin{array}{l}\text { Mobility } \\
\left(\mathrm{cm}^{2} / \mathrm{V}-\mathrm{s}\right)\end{array}$ & $\begin{array}{l}\text { Resistivity } \\
(\Omega \text {-cm })\end{array}$ & Carrier Type \\
\hline \multirow[t]{2}{*}{$\begin{array}{c}\text { pure } \mathrm{ZnO} \text { deposited } \\
\text { at } 150^{\circ} \mathrm{C}\end{array}$} & as & $-2.96 \times 10^{19}$ & & $8.29 \times 10^{-3}$ & $\mathrm{n}$ \\
\hline & as & $-2.22 \times 10^{12}$ & & $1.58 \times 10^{5}$ & $\mathrm{n}$ \\
\hline \multirow[t]{2}{*}{ Room temp. } & 350 & $-3.63 \times 10^{13}$ & & $4.68 \times 10^{5}$ & $\mathrm{n}$ \\
\hline & 450 & $-5.78 \times 10^{14}$ & & $1.18 \times 10^{3}$ & $\mathrm{n}$ \\
\hline \multirow{2}{*}{150} & as & $3.98 \times 10^{19}$ & & $3.47 \times 10^{-1}$ & $\mathrm{p}$ \\
\hline & 350 & $5.01 \times 10^{20}$ & & $7.35 \times 10^{-3}$ & $\mathrm{p}$ \\
\hline \multirow{2}{*}{200} & as & $1.86 \times 10^{13}$ & & $7.75 \times 10^{4}$ & $\mathrm{p}$ \\
\hline & 350 & $-6.45 \times 10^{11}$ & & $6.54 \times 10^{5}$ & $\mathrm{n}$ \\
\hline \multirow{2}{*}{250} & as & $1.50 \times 10^{12}$ & & $1.26 \times 10^{5}$ & $\mathrm{p}$ \\
\hline & 350 & $1.71 \times 10^{10}$ & & $3.06 \times 10^{7}$ & $\mathrm{p}$ \\
\hline
\end{tabular}


films. Since glass was used as the substrate, it is definite that the electrical properties measured were totally from the films. Among Ag doped thin films, only RT deposited thin films showed $n$-type conduction, and the others showed $p$-type conduction. Although RT deposited thin film had $n$-type conduction, electron concentration was several orders lower than $2.96 \times 10^{19} / \mathrm{cm}^{3}$ of undoped

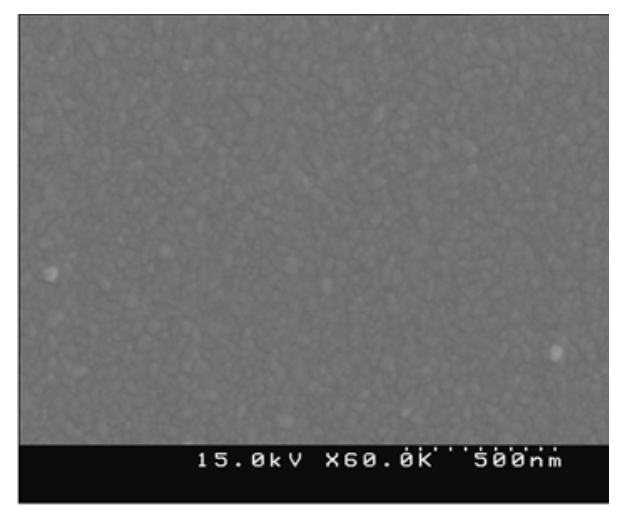

(a)

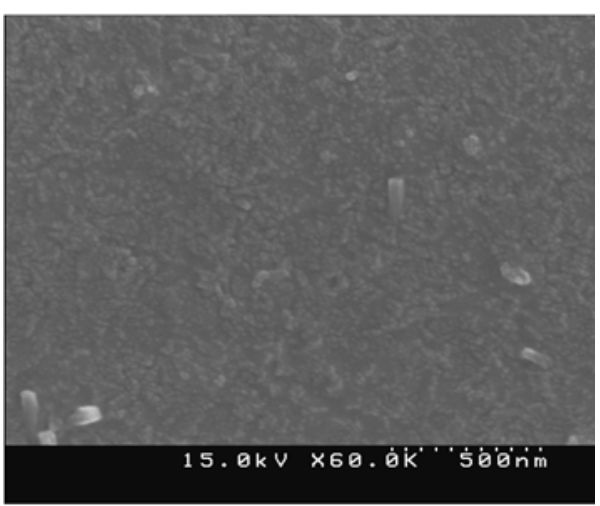

(b)

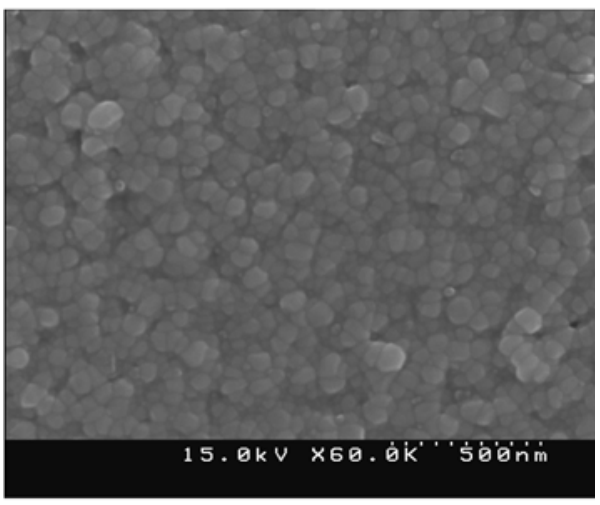

(c)

Fig. 5. Surface microstructures of the films grown at $150^{\circ} \mathrm{C}$; (a) as-grown, (b) annealed at $350^{\circ} \mathrm{C}$, and (c) annealed at $650^{\circ} \mathrm{C}$.
$\mathrm{ZnO}$. It is concluded that $\mathrm{Ag}$ acceptors compensated electrons from native donors but RT was such a low temperature to activate $\mathrm{Ag}$ acceptors, thus the thin films still remained as $n$-type. Additionally, $\mathrm{Ag}$ is known as amphoteric dopant, which means that $\mathrm{Ag}$ can act not only as an acceptor occupying $\mathrm{Zn}$ site but also as a donor occupying interstitial site. ${ }^{26)}$ Substitution of a large cation $\mathrm{Ag}$ on the smaller zinc site and/or incorporation into interstitial site should cause an increased in lattice spacing. However, the observed decrease in lattice spacing, as shown in Figure 6, is inconsistent with what we have expected. H. S. Kim et al. ${ }^{12)}$ also reported the inconsistency between substitution of large phosphorus (P) anion on the smaller oxygen site and decrease in lattice $d$-spacing. They suggested that an alternative location for the $\mathrm{P}$, possibly as an antisite $\mathrm{P}_{\mathrm{Zn}}$ defect, brought the inconsistency. In this point of view, inconsistency observed in Figure 6 can be explained by adopting antisite $\mathrm{Ag}_{\mathrm{O}}$ defect. Because $\mathrm{Ag}^{+}$has the smaller ion size of $1.00 \AA$ than $1.38 \AA$ of $\mathrm{O}^{2-}$, if $\mathrm{Ag}$ is incorpo- rated in interstitial site, the film will show the reduced lattice $d$ spacing.

Electron concentration of RT deposited thin film increased with increasing annealing temperature of up to $450^{\circ} \mathrm{C}$. As mentioned above, Ag acceptor atoms evaporated during the post-annealing process, leading to an increase in the electron concentration. However, above $450^{\circ} \mathrm{C}$, it was not possible to make ohmic contact between electrode and film due to the high resistance of the film. It is considered that very rough surface caused by $\mathrm{Ag}$ evaporation acted as scattering center of electrical flow. The thin film deposited at $150^{\circ} \mathrm{C}$ showed the highest hole
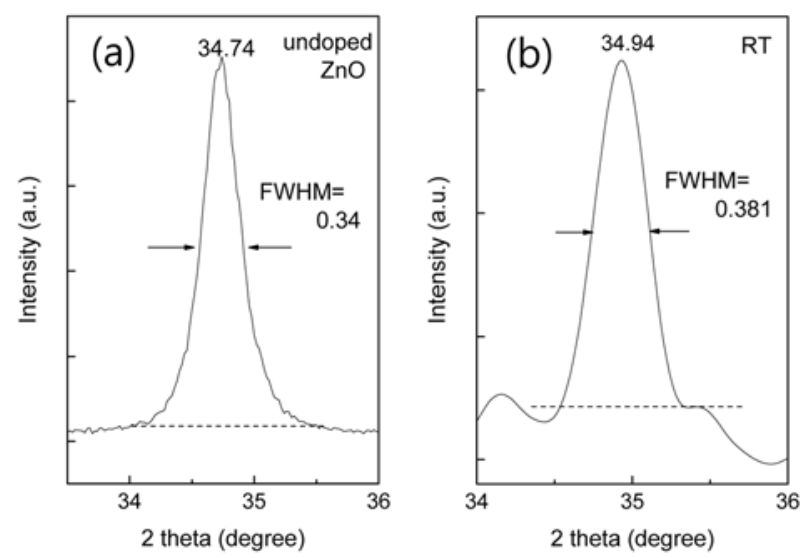

Fig. 6. X-ray diffraction patterns of (002) plane; (a) undoped $\mathrm{ZnO}$ film grown at $150^{\circ} \mathrm{C}$, (b) $\mathrm{ZnO}: \mathrm{Ag}$ film deposited at RT. 

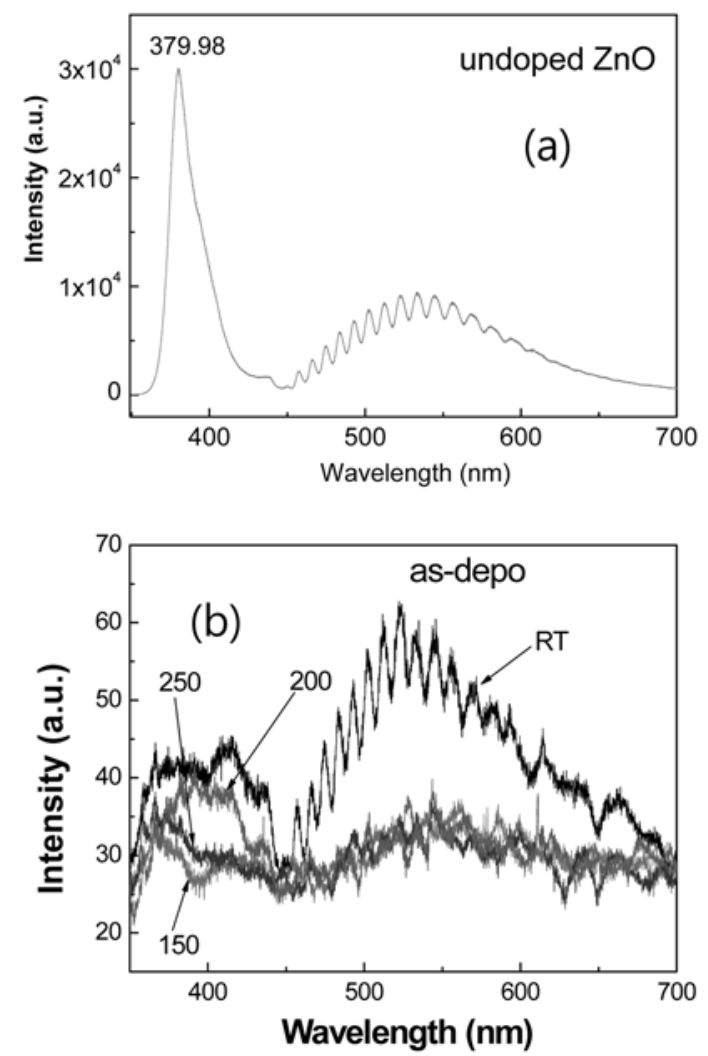

Fig. 7. RT PL spectra; (a) undoped $\mathrm{ZnO}$ film grown at $150^{\circ} \mathrm{C}$, (b) as-grown thin films deposited at various temperatures. The deposition temperatures are indicated by arrows in the figure.

concentration of $3.98 \times 10^{19}$ and this is higher than the values reported previously. ${ }^{18-19)}$ The hole concentrations of as-deposited $\mathrm{ZnO}: \mathrm{Ag}$ films reduced with increasing deposition temperature, because $\mathrm{Ag}$ content reduced gradually according to the deposition temperature.

PL spectra of the $\mathrm{ZnO}: \mathrm{Ag}$ thin films with deposition temperature were measured at RT and the results of asgrown films are illustrated in Figure 7 and 8. Due to the intrinsic defects, which are always present in $\mathrm{ZnO}, \mathrm{PL}$ spectrum of undoped $\mathrm{ZnO}$ in Figure 7 (a) exhibits deeplevel visible emission in addition to the near band-edge UV emission. However, Ag doped ZnO PL spectra of asgrown films did not show clear emission bands as shown in Figure 7 (b). They only exhibit very weak emission bands including near band-edge UV band and broad visible emission band.

Figure 8 shows PL spectra of films annealed at $350^{\circ} \mathrm{C}$. All films exhibit quite different PL intensities. The PL spectrum of RT deposited films shows a relatively stronger defect-related broad green emission as shown in Figure 8 (a). The PL of film deposited at $150^{\circ} \mathrm{C}$ and
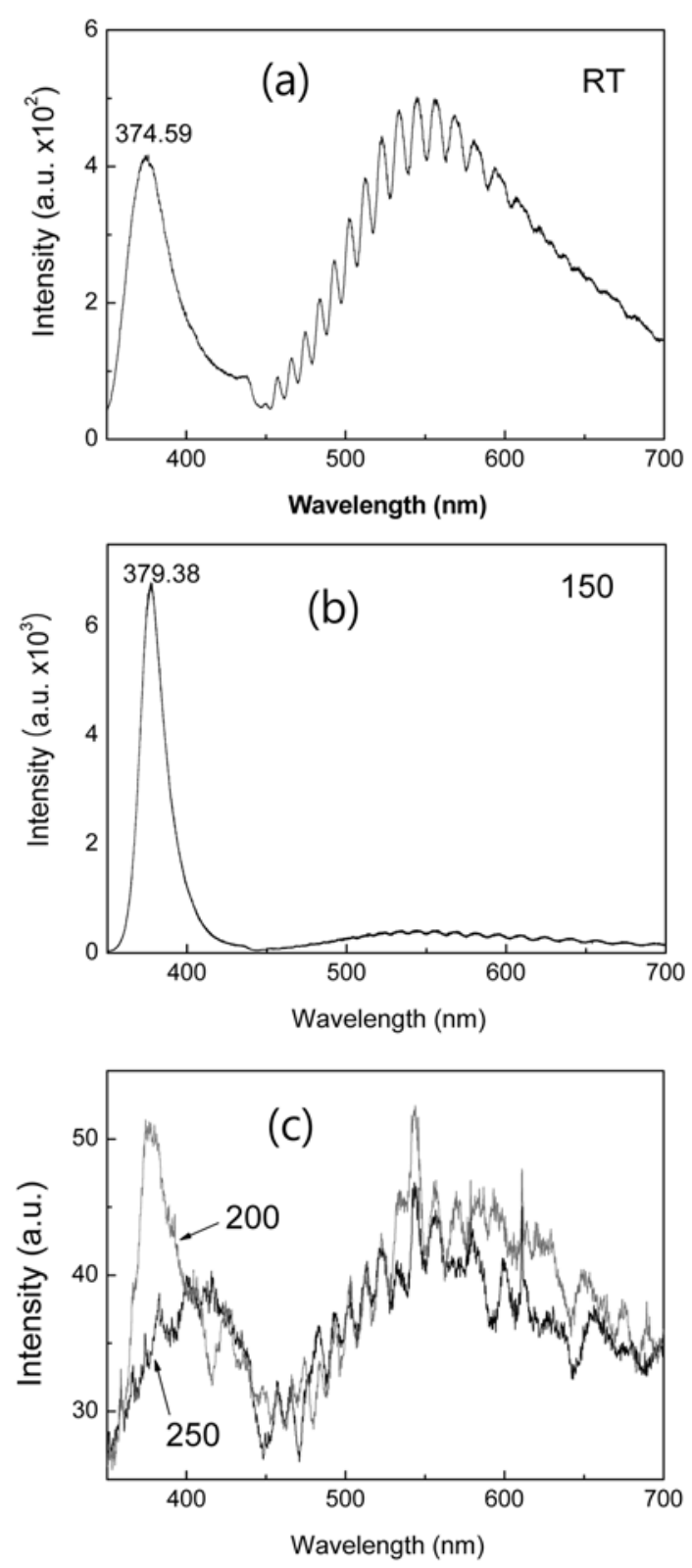

Fig. 8. RT PL spectra of the films annealed at $350^{\circ} \mathrm{C}$; (a) grown at RT, (b) grown at $150^{\circ} \mathrm{C}$, and (c) grown at 200 and $250^{\circ} \mathrm{C}$.

annealed at $350^{\circ} \mathrm{C}$ shows very strong near band-edge UV emission positioned at $379.38 \mathrm{~nm}$ and the ratio of $I_{V I S} / I_{U V}$ was as low as 0.05 , while that of as-grown undoped $\mathrm{ZnO}$ deposited at $150^{\circ} \mathrm{C}$ was 0.31 . Li Duan et al. ${ }^{17)}$ reported the enhancement of UV emission from $\mathrm{ZnO}$ films by $\mathrm{Ag}$ doping. They suggested the holes existing in the interface between $\mathrm{Ag}_{2} \mathrm{O}$ nanoclusters and $\mathrm{ZnO}$ grains as reasons for enhancement of UV emission. They insisted that the electrons in $\mathrm{ZnO}$ arrive at the interface easily because of their short mean free path and the Coulomb force based 

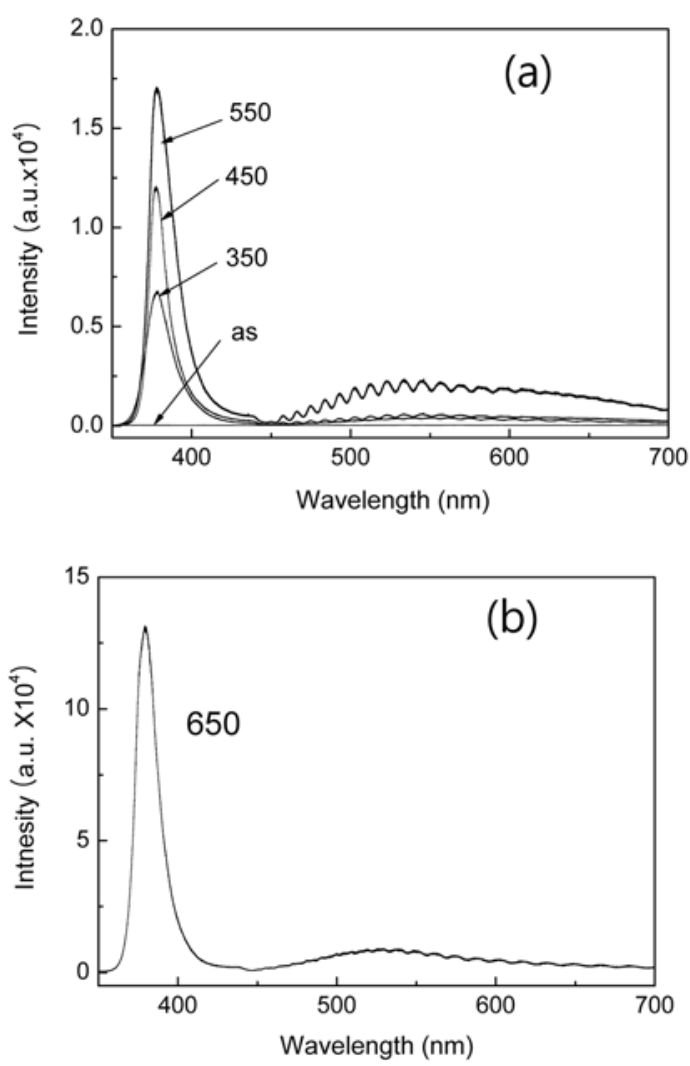

Fig. 9. RT PL spectra of the films grown at $150^{\circ} \mathrm{C}$ according to the annealing temperature; (a) as-grown and annealed at $350-550^{\circ} \mathrm{C}$, and (b) annealed at $650^{\circ} \mathrm{C}$. The annealing temperatures are indicated in the figures.

on quantum confinement effect, therefore the UV emission was enhanced. The PL spectrum of films deposited at $200^{\circ} \mathrm{C}$ also showed slightly increased emission intensity, but that of $250^{\circ} \mathrm{C}$ deposited film did not increase as much as the others did, despite annealing at $350^{\circ} \mathrm{C}$.

Figure 9 shows the changes in PL spectra of films deposited at $150^{\circ} \mathrm{C}$ according to annealing temperature. Both emission intensity of near band-edge UV and defect related green emission increased with increasing annealing temperature. Especially, the PL intensity of films annealed at $650^{\circ} \mathrm{C}$ increased enormously.

\section{Conclusion}

The effect of the deposition and annealing temperature on structural, electrical and optical properties of $\mathrm{Ag}$ doped $\mathrm{ZnO}$ thin films by e-beam evaporation method were studied. It is noticed that the deposition temperature affects the content of $\mathrm{Ag}$ in the film and $\mathrm{Ag}$ atoms can easily be evaporated during thermal annealing. The asgrown thin films deposited at $150-250^{\circ} \mathrm{C}$ showed $p$-type conduction, although the films deposited at RT exhibited $n$-type conduction. The PL spectra of as-grown $\mathrm{ZnO}$ did not show clear emission bands, while the emission intensity increased as the post-annealing temperature increased. The film deposited at $150^{\circ} \mathrm{C}$ and annealed at $350^{\circ} \mathrm{C}$ exhibited the lowest value of $I_{v i s} / I_{u v}$ of 0.05 .

\section{Acknowledgement}

This work was supported by the Second Stage of Brain Korea 21 Project in 2007.

\section{References}

1. D. C. Look, D. C. Reynolds, C. W. Litton, R. L. Jones, D. B. Eason and G. Cantwell, Appl. Phys. Lett., 81(10), 1830 (2002).

2. D. C. Look and J. W. Hemsky, Phys. Rev. Lett., 82(12), 2552 (1999).

3. S. B. Zhang, S. H. Wei and Alex Zunger, Phys. Rev. B, 63, 075205 (2001).

4. K. lp, M. E. Overberg, Y. W. Heo, D. P. Norton, S. J. Pearton, C. E. Stutz, B. Luo, F. Ren, D. C. Look and J. M. Zavada, Appl. Phys. Lett., 82(3), 385 (2003).

5. K. lp, M. E. Overberg, Y. W. Heo, D. P. Norton, S. J. Pearton, S. O. Kucheyev, C. Jagadish, J. S. Williams, R. G. Wilson and J. M. Zavada, Appl. Phys. Lett., 81(21), 3996 (2002).

6. Chirs G. Van de Walle, Phys. Rev. Lett., 85(5), 1012 (2000).

7. C. H. Park, S. B. Zhang and S.-H. Wei, Phys. Rev. Lett., 66, 073202 (2002).

8. O. F. Schirmer and D. Zwingel, Solid State Commun., 8, 1559 (1970).

9. Ü. Özgür, Ya. I. Alivov, C. Liu, A. Teke, M. A. Reshchikov, S.Doan, V. Avrutin, S.-J. Cho, and H. Morkoç, J. Appl. Phys., 98, 041301 (2005).

10. A. N. Georgobiani, A. N. Gruzintsev, V. T. Volkov, M. O. Vorobiev, V. I. Demin and V. A. Dravin, Nucl. Instrum. Meth. A, 514, 117 (2003).

11. A. Zeuner, H. Alves, J. Sann, W. kriegseis, C. Neumann, D. M. Hofmann, B. K. Meyer, A. Hoffmann and U. Haboeck, M. Straßburg and A. Kaschner, Phys. Stat. Sol. c, 1(4), 731 (2004).

12. H. S. Kim, S. J. Pearton and D. P. Norton, J. Appl. Phys., 102, 104904 (2007).

13. E. PrzeŸdziecka, E. Kamiñska, I. Pasternak, A. Piotrowska and J. Kossut, Phys. Rev. B, 76, 193303 (2007).

14. Y. R. Ryu and T. S. Lee, Appl. Phys. Lett., 83(1), 87 (2003).

15. H. S. Kang, G. H. Kim, D. L. Kim, H. W. Chang, B. D. Ahn and S. Y. Lee, Appl. Phys. Lett., 89, 181103 (2006).

16. E. Mollwo, G. Müller and P. Wagner, Solid State Commun., 13, 1283 (1973).

17. Li Duan, Bixia Lin, Weiying Zhang, Sheng Zhong and Zhuxi Fu, Appl. Phys. Let., 88, 232110 (2006). 
18. H. S. Kang, B. D. Ahn, J. H. Kim, G. H. Kim, S. H. Lim, H. W. Chang and S. Y. Lee, Appl. Phys. Lett., 88, 202108 (2006).

19. B. D. Ahn, H. S. Kang, J. H. Kin, G. H. Kim, H. W. Chang and S. Y. Lee, J. Appl. Phys., 100, 093701 (2006).

20. Y. Yan, M. M. Al-Jassim and S.-H. Wei, Appl. Phys. Lett., 89, 181912 (2006).

21. The MERCK INDEX, $11^{\text {th }}$ edition, p.8475, Susan Budavari, Merck \& Co., Inc., New Jersey, USA (1989).

22. J. B. Lee, S. H. Kwak and H. J. Kim, Thin Solid Films,
423, 262 (2003).

23. N. Fujimura, T. Nishihara, S. Goto, J. Xu and T. Ito, J. Cryst. Growth, 130, 269 (1993).

24. Y. Zhang, G. Du, D. Liu, X. Wang, Y. Ma, J. Wang, J. Yin, X. Yang, X. Hou and S. Yang, J. Cryst. Growth, 234, 439 (2002).

25. L. N. Dinh, M. A. Schildbach, M. Balooch and W. McLean II, J. Appl. Phys., 86(2), 1149 (1999).

26. J. Fan and R. Freer, J. Appl. Phys., 77(9), 4795 (1995). 